\title{
Política na sala de aula: uma proposta interdisciplinar a partir da Antiguidade
}

\section{Politics in the Classroom: An Interdisciplinary Proposal From Antiquity}

Priscilla Gontijo Leite

Universidade Federal da Paraíba, João Pessoa, Paraíba / Brasil priscillagontijo@gmail.com

Lucas Consolin Dezotti

Universidade Federal da Paraíba, João Pessoa, Paraíba / Brasil lucascdz@gmail.com

Resumo: Diversas palavras do nosso vocabulário político são originárias da Antiguidade Clássica - democracia, aristocracia, oligarquia, tirania - e são utilizadas com frequência no cotidiano. Contudo, o ensino sobre o entendimento dessas noções apresenta falhas, pois está muitas vezes centrado numa abordagem conceitual, não numa perspectiva histórica, deixando de demonstrar para os alunos que esses conceitos foram formulados em um determinado período da história humana - a saber, na Antiguidade. Assim, pautando-se na promoção de uma abordagem que valorize o aspecto histórico para o entendimento de conceitos, foi elaborado o projeto Prolicen "Vocabulário político da antiguidade: reflexões para o exercício da cidadania", objeto deste texto. Aqui vamos relatar como a perspectiva interdisciplinar, que agrega conhecimentos de História e Letras Clássicas, foi essencial para o desenvolvimento do projeto, cujo resultado principal foi a elaboração de material didático com trechos de fontes antigas (Heródoto, Aristóteles, Políbio e Tito Lívio), 
visando facilitar a utilização dessas fontes por professores da educação básica e superior. O grande diferencial do trabalho é a apresentação bilíngue dos textos (grego ou latim e português), provendo acesso ou despertando interesse para as línguas do passado, provando que a Antiguidade não está tão distante de sua realidade.

Palavras-chave: ensino; política; letras clássicas; história antiga.

Abstract: Several words from our political vocabulary originate from Classical Antiquity - democracy, aristocracy, oligarchy, tyranny - and are often used in daily life. However, the classroom approach of these concepts reveals some flaws. When addressing these issues, teachers often center their explanations on a conceptual non-historical perspective, and fail to demonstrate to students that these concepts were formulated in a given period of Human History - namely, in Antiquity. The object of this paper, Project Prolicen "Political Vocabulary of Antiquity: Reflections for the Exercise of Citizenship", was elaborated with the objective to promote a teaching approach that values a historical aspect for the understanding of such concepts. In this paper we are going to report how the interdisciplinary perspective, which combines knowledge of both History and Classical Literature, was essential for the development of this Project. We will also comment on its main result: the elaboration of courseware containing excerpts from ancient sources (Herodotus, Aristotle, Polybius and Livy), with the aim to facilitate the use of such sources by primary and higher education teachers. This work stands out for its bilingual presentation of the texts (Greek/Latin and Portuguese), which provides access to or arouses interest in the languages of the past, and aims to prove that Antiquity is not so far from our reality.

Keywords: teaching; politics; classical literature; ancient history.

Recebido em: 8 de fevereiro de 2017. Aprovado em: 16 de maio de 2017. 


\section{Introdução}

O atual cenário político brasileiro conduz a reflexões que remetem à forma como a política é discutida nos diversos segmentos da sociedade, bem como à prática do ensino dessa temática nas escolas da educação básica. Pensando nessas duas perspectivas, o projeto Prolicen "Vocabulário político da Antiguidade: reflexões para o exercício da cidadania" foi elaborado a fim de estudar o vocabulário político utilizado no cotidiano a partir da Antiguidade Clássica. O intuito é produzir um material que promova a reflexão sobre termos comuns no nosso cotidiano - tais como democracia, república, aristocracia, oligarquia, monarquia, tirania - pensando em como eles foram cunhados e utilizados na Antiguidade e como determinados sentidos prevaleceram sobre outros, formando a ideia que nós comumente temos a respeito desses termos.

Além da intenção reflexiva no que concerne a termos políticos, parte do projeto tem por intuito auxiliar o ensino de História Antiga na educação de nível fundamental II, médio e superior, oferecendo para os docentes um suporte para trabalhar com textos literários, a partir do qual se espera que o docente possa estimular seus alunos a pensar sobre a política numa perspectiva diacrônica, problematizando os conceitos que são frequentemente utilizados no cotidiano. Com isso, o aluno terá a possibilidade de conhecer o rico tema das formas de governo, suscitando reflexões sobre as diversas maneiras de se atuar na esfera política e a polivalência do conceito de cidadania.

\section{Metodologia}

Para o desenvolvimento do projeto, utilizamos como inspiração a metodologia proposta na História das palavras, desenvolvida por Louis Gernet no início do século XX, que busca uma ação interdisciplinar entre várias áreas do conhecimento, como História, Letras e a Sociologia. $\mathrm{O}$ próprio helenista não a concebia como um método rigoroso, mas uma

\footnotetext{
${ }^{1}$ Discentes participantes: Bruno Ramalho de Figueirêdo, Danusia Oliveira Ferreira, Felipe Matheus dos Santos Silvestre, Heloísa Hiranoyama Maia, Lívia Maria da Silva, Raissa do Nascimento Fernandes.
} 
atitude para diferenciar seu trabalho da filologia tradicional. Nota-se a forte influência da sociologia durkheimiana na sua análise linguística, e foi esse o caminho utilizado para pensar as relações entre língua e sociedade. Para ele, na medida em que o significado de uma palavra está relacionado a seu contexto histórico, a língua se torna um objeto privilegiado de análise histórica, sobretudo as transformações do vocabulário.

Esta inspiração investigativa, centrada nas relações entre a história e as palavras, foi utilizada por estudiosos como Marcel Detienne, Nick Fisher e Louise Bruit Zaidman. Em todos, há o entendimento da organização do meio social através do estudo das palavras, uma vez que a organização do mundo ocorre a partir do processo de qualificação linguística das coisas existentes, que, além de nomeá-las, também as adjetiva. Isto gera um sistema de classificação, e seu estudo pode demonstrar a hierarquia de valores presente na sociedade, bem como a lógica na qual se estruturam as relações sociais (GERNET, 2002, p. 9-10). Assim, uma estrutura social corresponde a uma disposição linguística, e mudanças em uma, de alguma maneira, se traduzem na outra. Também há a possibilidade de apreender desse sistema as diferentes modalidades de pensamento que existem no interior de um grupo, o que implica a coexistência de diversas modalidades de "verdades", que podem até mesmo ser opostas entre si (VEYNE, 1984, p. 39).

Além disso, a linguagem demonstra as práticas de um grupo, e ao estudá-la também se compreendem seus comportamentos. Como a linguagem está envolvida por relações sociais, e a palavra demonstra uma prática social, qualquer transformação no meio pode implicar numa alteração na linguagem, de modo que, a partir da mudança do sentido de uma palavra, pode-se analisar as modificações ocorridas numa sociedade. Em suma, a perspectiva histórica aplicada ao estudo das palavras possibilita perceber as alterações de sentidos e de usos de uma palavra ao longo do tempo, e com isso perceber as mudanças que a sociedade sofreu.

A aplicação de tal método promove resultados ainda mais favoráveis em uma sociedade em que a palavra desempenha um papel fundamental na organização da cidade. Esse é o caso da Antiguidade greco-romana, em que o exercício da palavra era essencial para o 
funcionamento das instituições. Era por meio da palavra pronunciada que o cidadão ateniense, por exemplo, intervinha nos assuntos da cidade. Dessa forma, a participação por meio da palavra era determinante no domínio social e político (DABDAB TRABULSI, 2006, p. 130).

Essa metodologia foi utilizada no projeto com as devidas adaptações, para que se cumprisse o cronograma preestabelecido pelo Programa e se produzissem resultados dirigidos à prática docente. Com isso, concentrou-se a atenção na leitura de fontes antigas a partir do eixo da construção do vocabulário político.

Por fim, é importante destacar que, desde o início, em todo o processo de trabalho, a equipe interdisciplinar buscou colocar em prática a sua principal ideia norteadora, que foi a valorização da discussão como uma etapa da formação para a atuação política do sujeito. Assim, a definição das palavras ligadas ao vocabulário político a serem pesquisadas, a separação dos autores a serem trabalhados, a forma de utilizar esses autores em sala de aula e a maneira como os resultados seriam divulgados foram todas propostas construídas coletivamente.

\section{Percurso}

Num primeiro momento, os alunos foram introduzidos na discussão acerca das formas de governo e das práticas políticas do mundo Antigo, com o que eles puderam realizar uma breve pesquisa lexical sobre os termos políticos de seu interesse. Dentre os vários autores e temas que surgiram, decidiu-se concentrar as pesquisas na questão das formas de governo conforme o testemunho de quatro deles - Heródoto (484-425 a.C.), Aristóteles (384-322 a.C.), Políbio (203-120 a.C.) e Tito Lívio (59 a.C.17 d.C. $)^{2}$-, todos ilustres representantes de suas respectivas (e diferentes) épocas e com frequência objetos atuais de estudos no âmbito universitário.

\footnotetext{
${ }^{2}$ Para o desenvolvimento da primeira etapa do projeto foram analisadas as seguintes obras: História, principalmente o livro III, de Heródoto; A política, especialmente os livros III e IV, de Aristóteles; História, com o foco no livro VI, de Políbio; A história de Roma desde sua fundação, livro I, de Tito Lívio.
} 
Definidos os autores e os termos a serem analisados, iniciouse uma segunda rodada de discussões, com o objetivo de obter um panorama da atual situação do ensino de História Antiga nos níveis médio e fundamental II. Para tanto, foram avaliados alguns exemplares de livros didáticos, nos quais foram encontrados casos flagrantes de anacronismo e, por vezes, uma abordagem pouco articulada com uma reflexão atualizada sobre o período histórico em questão.

Paralelamente ao levantamento lexical e à discussão do ensino da Antiguidade, também se discutiu uma maneira adequada de formatar esse conteúdo para ser levado às salas de aulas. Surgiram muitas ideias de aplicação da reflexão sobre o vocabulário político nas salas de aulas, como a elaboração de jogos didáticos e a utilização de filmes. Contudo, verificou-se que a concretização dessas ideias exigia a realização de pesquisas mais aprofundadas e a elaboração de um material de apoio, e então se decidiu pelo desenvolvimento de fichas de análise.

São fichas que permitem abordar diversas problemáticas ligadas à tradução e ao uso histórico dos termos (incluindo o uso vigente), temas que permearam nossas reuniões e são discutidos a partir de trechos das fontes supracitadas, trabalhadas de forma a facilitar sua eventual utilização pelo professor. As fichas seguem a seguinte disposição: (a) dados informativos sobre o autor e a obra; (b) texto em grego ou latim e tradução em português, dispostos lado a lado, com destaque para os termos relevantes do vocabulário político; (c) um pequeno léxico comentado, para informar especialistas e leigos sobre as possibilidades de leitura do texto na língua de partida; (d) comentários de caráter teórico e contextual, esclarecendo momentos históricos e trazendo discussões relativas ao vocabulário político; (e) sugestões de debate para a sala de aula. ${ }^{3}$

Assim, os alunos passaram a trabalhar diretamente com as fontes documentais, dedicando-se ao levantamento e à delimitação de trechos pertinentes; trabalho importante para se atingir um dos objetivos do projeto, que é a divulgação dos textos clássicos, principalmente entre os estudantes, mostrando sua importância para a formação do pensamento ocidental. Além disso, há o interesse de analisar as diferentes maneiras

\footnotetext{
${ }^{3}$ Um exemplo de ficha completa está reproduzido em anexo.
} 
pelas quais essas obras foram traduzidas e identificar o impacto da interpretação do texto sobre as escolhas do tradutor.

\section{Resultados}

Tomemos como exemplo a discussão em torno do termo democracia, um dos mais polêmicos do vocabulário político. O termo, que perpassa vários autores da Antiguidade, hoje é a forma de governo que chama mais atenção nos debates com o público, visto que denominamos nosso governo de democrático.

A democracia é o regime político que mais se expandiu nos últimos dez anos, com um aumento de $18 \%$. Atualmente, calcula-se que $45 \%$ dos países do mundo vivem em uma democracia (MITCHELL, 2015 , p. 1). Boa parte das pessoas sabe que a democracia surgiu na Grécia, mas desconhece as multiplicidades dos regimes políticos de cada pólis e as ferrenhas críticas dirigidas à democracia, como demonstra $\mathrm{o}$ documento encontrado no corpus de Xenofonte:

Em qualquer parte do mundo, a classe alta opõese à democracia. Nas camadas superiores há pouca desordem e injustiça e existe a preocupação com a preservação da boa moral, enquanto que entre o povo reina a ignorância, a desordem e a perversidade; a pobreza faz com que se cometa atos censuráveis, sendo a falta de educação e a ignorância de alguns o resultado da falta de dinheiro (PSEUDOXENOFONTE, A constituição dos atenienses, 1.5).

$\mathrm{Na}$ Antiguidade, os intelectuais, na sua esmagadora maioria, não concordavam com a democracia, e a explicação quase sempre recaía na impossibilidade de o povo governar de forma sábia e justa, argumentação que continua em voga até os dias atuais, como se vê tristemente na realidade brasileira diante do ocorrido em 2016 e 2017. Como Finley ressaltou em Democracia antiga e moderna (1988, p. 2636), na Antiguidade não foi formulada uma verdadeira teoria democrática, e muito do que sabemos hoje do funcionamento desse regime deve-se 
principalmente aos seus críticos - historiadores e filósofos sérios, como Tucídides, Platão e Aristóteles, mas também a um dramaturgo ácido e bem-humorado como Aristófanes.

A desaprovação da democracia por parte de autores tão consagrados da tradição clássica fez com que o vocábulo praticamente desaparecesse da linguagem popular ocidental até o século XVIII; quando utilizado, sempre trazia conotações negativas. De acordo com Finley (1988, 22-23), na França são raras as ocorrências do termo em sentido positivo. Tal quadro se inverte a partir do processo de independência dos Estados Unidos e da Revolução Francesa, que, ao romper com sua tradição imediata, buscaram construir outra e, para isso, recorreram aos antigos. A democracia muda de sentido e passa a ser compreendida como uma forma de governo fortemente ligada à liberdade, o que não corresponde ao uso dos antigos atenienses, ${ }^{4}$ cuja democracia conhecemos com mais detalhes por causa das fontes que chegaram até a posteridade, inclusive produzidas por não atenienses, como é o caso de Aristóteles. Conforme esses testemunhos, a democracia em Atenas estava ligada a uma busca por igualdade - não uma igualdade socioeconômica, mas igualdade de acesso à esfera política: todo e qualquer cidadão deveria poder exercer a política.

Também é em Atenas que o termo "democracia" aparece de maneira impressa no segundo quartel do século V a.C. A palavra é formada por dois elementos: demos ("povo") e kratos ("força", "soberania"), formação que se distingue de outros termos políticos já então consolidados no vocabulário grego, como monarquia e oligarquia, compostos por monos/oligos ("um"/“poucos") e arkhé ("poder"): a diferença entre kratos e arkhé é representativa da forma como antigos

\footnotetext{
${ }^{4}$ Uma das preocupações no decorrer das discussões do projeto foi caracterizar a democracia ateniense como uma dentre várias experiências democráticas do mundo antigo e salientar que ela não pode ser estendida para toda a Antiguidade. Tal posição está em sintonia com estudos atuais que valorizam a multiplicidades de regimes no mundo políade, como o levantamento desenvolvido por Hansen em An Inventory of Archaic and Classical Poleis (2004). Tal postura se faz necessária em tempos de globalização para demonstrar a possibilidade de construir modelos democráticos que valorizem aspectos culturais próprios e que sejam autônomos, não atrelados a uma imposição dos mercados econômicos.
} 
entendiam esses regimes políticos. Essa reflexão, por sua vez, também nos convida a voltar o olhar para nosso sistema político: afinal, de que se compõe a democracia que estamos construindo?

$\mathrm{Na}$ literatura, se não considerarmos o tratado ateniense com Cólofon de 447-446 a.C. (IG, 3.37.49), o vocábulo aparece pela primeira vez em Heródoto, no chamado "Diálogo dos persas" (Histórias, 3.80.3), que apresenta uma primeira diferenciação das formas de governo, segundo critérios quantitativos, que será gravada de maneira determinante na mentalidade ocidental.

O "Diálogo dos persas" narra a discussão de um grupo de sete nobres persas a respeito do melhor regime a ser adotado. A Pérsia vivenciava um vazio de poder depois da morte de Cambieses e da destituição do governo dos magos, que tomaram o poder por meio de uma conspiração e foram banidos pelo excesso de abusos. Na conversa entre Otanes, Megábizos e Dário, três formas de governo são apresentadas e denominadas por critérios quantitativos. As virtudes são expostas pelos proponentes, e os vícios, pelos adversários. Otanes inicia a discussão querendo convencer os persas a adotarem a democracia (chamada por ele de isonomia). As características desse regime são o governo do povo (do plethos, não do demos), o sorteio, a isonomia, a prestação de contas, a exposição de todas as decisões para a comunidade: ${ }^{5}$

\footnotetext{
${ }^{5}$ Para a citação dos trechos de Heródoto, Aristóteles e Políbio, utilizamos parte do material levantado pelos alunos na elaboração das fichas, como texto grego e tradução para o português, com alguns destaques que chamam a atenção do leitor para termos do vocabulário político ou considerados fundamentais para a leitura. Na primeira fase do projeto (2016), cujos resultados são apresentados neste artigo, priorizamos o levantamento das fontes, o estudo do vocabulário e a montagem das fichas. Na segunda fase, atualmente em andamento (2017), o foco é a elaboração de traduções destinadas especialmente ao público de ensino médio. Por enquanto, as citações de Heródoto ainda se utilizam da tradução de Mário da Gama Kury (1998); já as traduções de Aristóteles e Políbio aqui citadas foram realizações recentes (2017), mas não publicadas, de Danusia Oliveira Ferreira e Bruno Ramalho de Figueirêdo, respectivamente.
} 
[...] O governo do povo, ao contrário, traz primeiro consigo o mais belo de todos os nomes: igualdade perante a lei, e em segundo lugar, nenhuma das injustiças cometidas por um governante único é cometida nele. Todas as funções são atribuídas através de sorteio, e seus detentores são responsáveis pelos atos praticados no exercício das mesmas, e todas as decisões são submetidas à assembleia popular. Exponho portanto a minha opinião, propondo que acabemos com o governo de um único homem e elevemos o povo ao poder, pois tudo está na maioria (HERÓDOTO, 1988, 3.80.6. Grifos nossos).

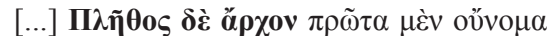

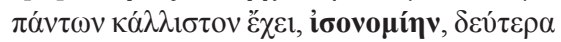

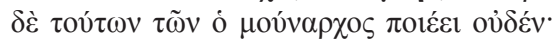

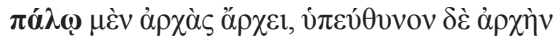

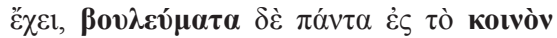

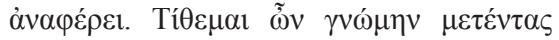

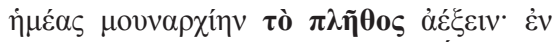

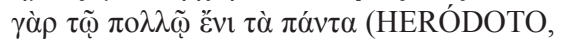
Histórias, 3.80.6. Grifos nossos).

No discurso de Otanes (3.80), é possível perceber a concepção de que todo cidadão estaria apto a governar. Megábizos, o segundo a falar (3.81), vai criticar justamente essa posição. Ele ataca ferrenhamente o regime proposto por Otanes, utilizando não o vocábulo isonomia, mas os termos demos e kratos, os formadores da palavra democracia. Para Megábizos, o melhor regime a ser adotado pelos persas é a oligarquia, argumentando com base nos critérios da utilidade e da educação: o povo é caracterizado como uma multidão inútil (homilos akhreios) e, por isso, a democracia não funcionaria; por isso, os melhores homens (aristoi androi) devem tomar as decisões, uma vez que fariam as melhores escolhas:

[...] salvar-nos da insolência de um tirano trocando-a pela insolência de uma multidão desenfreada seria absolutamente inadmissível. [...] Escolhamos um grupo dos melhores homens e entreguemo-lhes o poder; nós mesmos estaremos entre eles e é natural esperar dos melhores homens as melhores decisões (HERÓDOTO, 1988, 3.81.2-3. Grifos nossos).

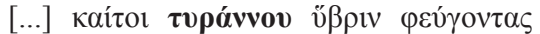

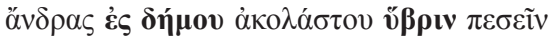

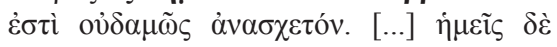

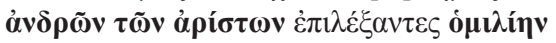

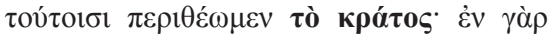

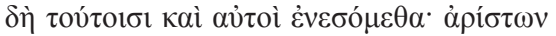
$\delta \grave{\varepsilon} \quad \dot{\alpha} v \delta \rho \tilde{\omega} v$ oikòs ă

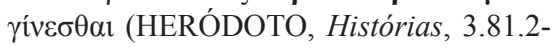
3. Grifos nossos).

O último a discursar é Dário (3.82), que inicia sua fala com uma interessante consideração, ao pontuar que em teoria todas as formas de governo são as melhores, e então passa a tecer críticas à democracia e à 
oligarquia, em defesa do sistema monárquico. Para ele, a monarquia é o melhor regime possível, pois os homens só sabem polemizar uns contra os outros, disputando sempre o primeiro lugar; para pôr fim a essas discórdias, apenas o aparecimento de uma figura dotada de liderança natural, que instauraria a monarquia. Na perspectiva de Dário, tanto a democracia quanto a oligarquia estão fadadas à corrupção; apenas a monarquia pode evitar a ruína da cidade, e para evitar todo esse percurso, o ideal seria logo a adoção da monarquia:

\footnotetext{
[...] numa oligarquia o fato de várias pessoas desejarem pôr o seu talento a serviço da coisa pública gera constantemente profundas divergências entre elas, $[\ldots]$ o resultado é a inimizade exacerbada [...]. Por outro lado, entregando-se o poder ao povo é impossível evitar a eclosão da incompetência, e quando há incompetência na administração da coisa pública, $[\ldots]$ as pessoas capazes de prejudicar a comunidade entram em conluio para prejudicá-la juntas. Essa situação se prolonga até aparecer alguém como paladino do povo para pôr fim a tal incompetência (HERÓDOTO, 1988, 3.82.3-4. Grifos nossos).
}

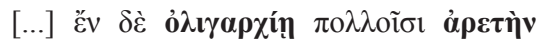

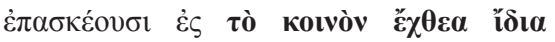

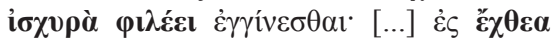

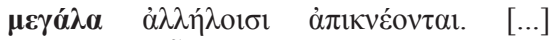

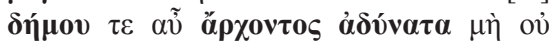

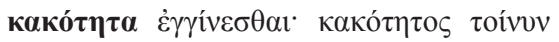

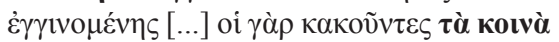

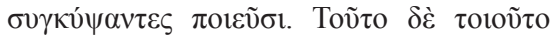

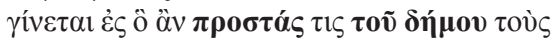

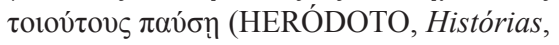
3.82.3-4. Grifos nossos).

No "Diálogo dos persas", termos como monarquia, oligarquia e democracia aparecem ao lado de outros que parecem ser utilizados como sinônimos, como tirania, governo dos melhores e isonomia. Porém, seu uso está bem marcado por conotações positivas e negativas. Por exemplo, nota-se o uso da palavra isonomia para qualificar positivamente o regime de muitos, já os críticos do regime adotam a palavra democracia. A mesma operação acontece com os pares governo dos melhores e oligarquia, e monarquia e tirania. Portanto, é possível perceber os percursos desses vocábulos e seu processo de consolidação na mentalidade grega.

O sucesso da palavra democracia no vocabulário político grego está ligado ao sucesso da experiência política ateniense, principalmente na fase do império marítimo, em que o funcionamento das instituições democráticas estava consolidado e o sistema de misthophoria (o 
pagamento pela participação política), garantida pela exploração do império, assegurava uma ampliação na participação popular.

Desse modo, no período de Aristóteles, o termo democracia estava totalmente consolidado na Grécia e correspondia a uma realidade histórica que servia de referência para outras cidades. Nota-se que o filósofo o utiliza na sua abordagem teórica sobre as formas de regime, que perpassa diferentes obras; neste trabalho, decidimos nos restringir ao tratado Política. Nessa obra, os regimes são pensados a partir da combinação entre a quantidade de pessoas no poder e a qualidade dos governantes quanto ao zelo pelo bem comum, e não simplesmente uma distinção quantitativa seguida pela apresentação de características, como no caso de Heródoto. Em Aristóteles, os regimes são dispostos na sua forma positiva e negativa, sendo o cuidado com a coletividade aquilo que os diferenciará. Assim, haverá seis formas de governo, três positivas - realeza (um), aristocracia (poucos), politeia (muitos) -, três negativas - tirania (um), oligarquia (poucos), democracia (muitos):

Dentre as monarquias, costumamos chamar de realeza aquela que visa o benefício coletivo. Quando o governo é de poucos, porém mais do que um, costumamos chamar de aristocracia (ou porque os melhores governam, ou porque visa o melhor para a cidade e para os que participam de sua coletividade). Já quando o conjunto dos cidadãos participa da política visando o benefício coletivo, é chamada pelo nome comum a todos os regimes: politeia. [...] São transgressões dos anteriores: a tirania, da realeza; a oligarquia, da aristocracia; e a democracia, da politeia. Porque a tirania é a monarquia voltada ao benefício do monarca, a oligarquia é o regime voltado ao benefício dos ricos, e a democracia é o regime voltado ao benefício dos pobres: nenhum deles, portanto, se volta para o que é vantajoso para o coletivo (ARISTÓTELES, [2017], 3.1279a 33-39, 1279b 4-10. Grifos nossos).

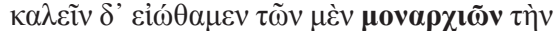

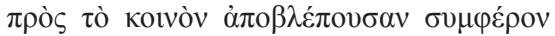

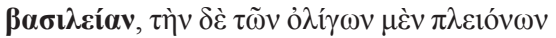

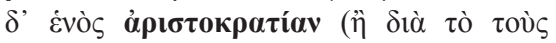

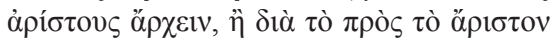

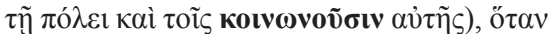

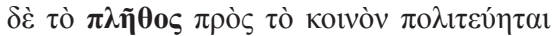

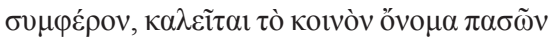

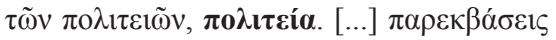

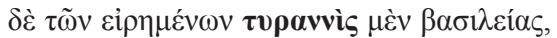

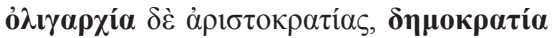

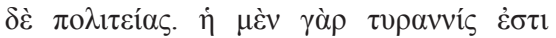

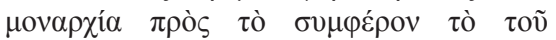

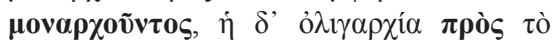

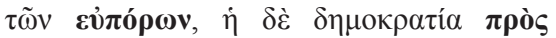

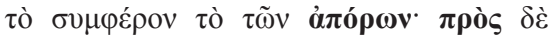

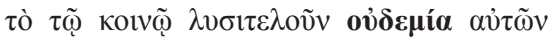
(ARISTÓTELES, Politica, 3.1279a 33-39, 1279b 4-10. Grifos nossos). 
Para Aristóteles, as formas de governo mais comuns são a democracia e a oligarquia, ambas consideradas corrompidas porque visam apenas uma parte da cidade, e não toda ela: a primeira visa apenas o interesse do demos; a segunda, apenas o interesse de um determinado grupo. O regime democrático, por sua vez, será caracterizado pelos termos liberdade (eleutheria), conjunto (plêthos) e a condição pobre (aporia). Os pobres, por serem abundantes na democracia e ocuparem o poder, levarão o regime a um desvio, pois se dará mais importância à vontade das massas populares e menos ao respeito e à obediência da lei (1292a 4-37, 1292b 411293a 10). Assim, na democracia de Aristóteles, a massa popular governa não sob o primado da lei, mas em vista do interesse particular, que consiste em instituir uma igualdade absoluta (simétrica e equidistante) de tudo e todos, à custa de um injusto nivelamento das diferenças.

Outro aspecto que chama a atenção na dicotomia entre oligarquia e democracia é a importância que Aristóteles atribui ao aspecto socioeconômico. Para ele, a verdadeira diferença entre os dois regimes reside na riqueza e na pobreza: se os pobres estão no poder, tem-se a democracia; se os ricos, oligarquia (1280a 1-6), independentemente de serem poucos ou muitos. Sendo assim, não é o critério quantitativo que determinaria uma democracia ou oligarquia, mas a categoria socioeconômica dos governantes. Na sua argumentação, o filósofo ainda constata que é mais comum os pobres serem mais numerosos que os ricos em qualquer cidade.

O que diferencia, principalmente, a democracia e a oligarquia uma da outra é a pobreza e a riqueza. Sempre que se governam com base na riqueza, quer sejam menos numerosos, quer sejam mais numerosos, este regime, inevitavelmente, será uma oligarquia. Sempre que os pobres governarem será uma democracia. Porém ocorre que, assim como dissemos, os ricos são poucos e os pobres são muitos. Pois, por um lado, poucos têm acesso a riqueza, por outro lado, todos participam da liberdade. Por estas causas, ambos estão em desacordo a respeito do regime político (ARISTÓTELES, [2017], 3.1279b 40-1280a 1-6. Grifos nossos).

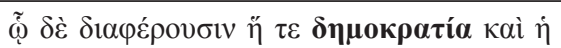

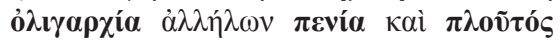

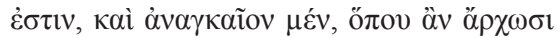

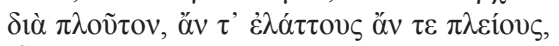

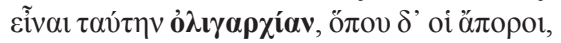

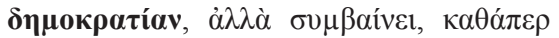

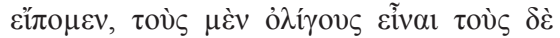

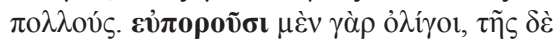

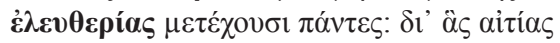

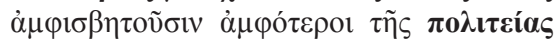
(ARISTÓTELES, Política, 3.1279b 401280a 1-6. Grifos nossos). 
Para nomear a forma positiva de democracia, Aristóteles utiliza o termo politeia, que em sua obra tem várias conotações: organização política, vida política, política, cidadania, poder político, governo, direito da pólis, direitos políticos, constituição, regime político. É como se se tratasse do regime ideal, sem um nome específico, apenas a referência à cidade como um todo, daí o equívoco de se traduzir por "república" ou mesmo "democracia". Desconsiderar tanto o sentido daquela palavra quanto o uso negativo desta pode levar a um anacronismo.

Mas a palavra democracia nem sempre aparece com conotações negativas na Antiguidade. Políbio, por exemplo, reverbera a divisão aristotélica entre bons e maus regimes, apresentando uma teoria também com seis formas de governo, três positivas e três negativas:

\begin{abstract}
Todo modelo de regime simples e instituído a partir de um único poder torna-se instável, pelo fato de desviar-se rapidamente para o vício que lhe é familiar e que o acompanha por natureza. [...] com os regimes, conforme a natureza de cada um, nasce um vício que os acompanha: a realeza vem acompanhada da chamada forma monárquica; a aristocracia, da forma da oligarquia; a democracia, da forma da selvageria e predomínio da força (POLÍBIO, [2017], 6.10.2-5. Grifos nossos).
\end{abstract}

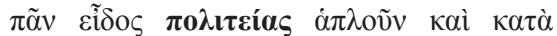

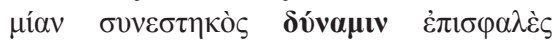

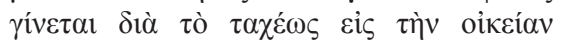

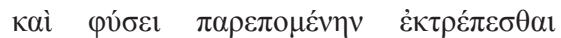

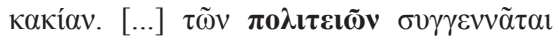

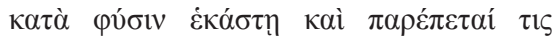

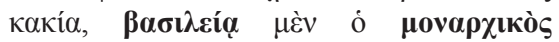

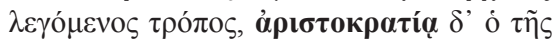

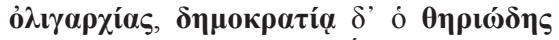

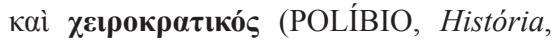
6.10.2-5)

Nota-se que a democracia é considerada positiva, caracterizada pelo respeito aos costumes e à tradição, principalmente quanto aos aspectos religiosos, à obediência às leis e à prevalência da vontade da maioria (cf. 6.4.4). Já sua versão degenerada para a selvageria e a violência recebe o nome de oclocracia (6.4.6).

No percurso de investigação dos três autores, nota-se que, independentemente de a democracia ser considerada uma forma positiva ou negativa, o poder de decisão da maioria é um aspecto sempre ressaltado. Quando é considerada positiva, outro ponto em comum entre Heródoto e Políbio é o respeito às leis. Assim, uma boa democracia seria justamente quando o povo é regido pelas leis e as obedece, já que são 
elas que lhe garantem o exercício no âmbito político. A relação entre lei, obediência e exercício da cidadania é algo que devemos com urgência debater no nosso cotidiano, com o objetivo de intensificar e melhorar a participação política dos brasileiros.

\section{Conclusões}

A preocupação em promover mecanismos que favoreçam a discussão e a aprendizagem sobre política na sala de aula motivou a concepção do projeto "Vocabulário político da Antiguidade: reflexões para o exercício da cidadania" para o Programa de Licenciatura da UFPB. Organizado de maneira a integrar os três elementos que sustentam a universidade pública - ao contemplar a pesquisa do discente sobre a fonte histórica, a elaboração de material didático para o ensino e a extensão dos resultados para professores e alunos da educação básica -, o projeto visa contribuir para o aprimoramento da formação profissional do discente, proporcionando ao licenciado a possibilidade de atuar de maneira prática e teórica com os conteúdos a que ele teve acesso na Universidade.

Constatou-se, no decorrer das pesquisas, que o ensino de conceitos essenciais para o entendimento do mundo político quase sempre é dado sem a devida contextualização histórica. Os livros didáticos costumam relegar esse conteúdo para o início do ensino de História e não fazem associações posteriores, especialmente sobre como a Antiguidade foi reapropriada ao longo dos séculos.

Ocorre que os livros didáticos são o material mais utilizado nas escolas no país, constituindo-se muitas vezes como único instrumento acessível para que o professor se mantenha atualizado. Ora, há mais de uma década ${ }^{6}$ especialistas em Antiguidade apontam os diversos problemas dessa área do saber nos livros didáticos (CORSÍ, 2010, p. 145; SILVA \& GONÇALVES, 2015, p. 4). A despeito disso, o livro didático parece manter o mesmo tratamento de meados do século passado com relação à Antiguidade,

\footnotetext{
${ }^{6}$ Um número especial da revista Hélade (2001) traz uma série de artigos a respeito da discussão entre o ensino de História Antiga e o livro didático. Disponível em: <http:// www.helade.uff.br/volume2numeroespecial.html>. Acesso em: 5 nov. 2016.
} 
que vem apresentada como algo exótico e distante, condicionando não só a visão dos alunos, mas também a postura e a abordagem do professor. $\mathrm{O}$ que haveria de positivo nessa representação - que é aguçar a curiosidade dos alunos, podendo estimular o envolvimento deles no processo de aprendizagem - não compensa o risco, grave, de que o conhecimento a respeito da Antiguidade seja reduzido a uma mera curiosidade, deslocado do mundo vivido, do qual ela constitui uma das fontes principais.

Até mesmo na universidade verifica-se que os alunos chegam com a percepção de que Antiguidade está relacionada com a fantasia, ficando a cargo de grandes heróis (quando não dos deuses) o protagonismo dos eventos, em detrimento de personagens e acontecimentos históricos. Os discentes trazem essas referências para a sala de aula na universidade sem saber como problematizá-las, e a História Antiga se torna um saber estanque, conteúdo fechado em si mesmo, sem nenhuma relação com a vida moderna. Formando os alunos universitários com essa percepção, há grande possibilidade de ela se perpetuar nas aulas do ensino fundamental e médio quando eles se tornarem professores.

A ausência de diálogo entre a Antiguidade e contemporaneidade e a carência de materiais para auxiliar os professores na realização dessa ponte constituem uma importante lacuna. Além disso, cumpre destacar a urgência de se pensar aspectos relacionados à política na atual conjuntura brasileira. Esta conduziu a uma polarização em que as partes articulam discursos que se mostram muitas vezes desprovidos de base conceitual mínima a respeito de termos políticos. Tal fato é preocupante, pois demonstra uma falha na formação da cidadania: se o sujeito não sabe o que é uma república, como poderá propor mudanças a esse sistema?

Uma forma de preencher essa lacuna é por meio da educação. O ensino da Antiguidade, em particular, pode auxiliar na formação da cidadania ao possibilitar que o sujeito reflita sobre a política a partir do entendimento da formação histórica de alguns conceitos considerados essenciais para a vida política atual, na medida em que o vocabulário político permite fazer um diálogo frutífero entre esses dois tempos aparentemente tão distantes. 
Sabe-se que nossa cultura, nosso direito, nossa filosofia e nosso idioma em algum momento banharam-se nas tradições gregas e romanas, e a melhor maneira de entender esse legado é a partir da leitura de documentos antigos, que costumam estar distantes da realidade do aluno. Ao oferecer o texto, a tradução, o léxico, o comentário, a bibliografia, espera-se fornecer alguma contribuição no sentido de viabilizar a construção de novas propostas político-pedagógicas para o ensino de Antiguidade no Brasil, possibilitando a criação de mecanismos que fomentem uma educação consoante com as necessidades escolares.

Essa proposta demandou um esforço de interdisciplinaridade, tendo-se buscado estabelecer um diálogo intenso e produtivo entre a História e as Letras Clássicas, já que ambas utilizam dessas fontes nas suas reflexões teóricas. A equipe de trabalho, composta por professores e alunos desses dois cursos, concretizou essa parceria essencial para o sucesso do desenvolvimento da metodologia, em um curto período de tempo, promovendo uma frutífera troca de experiências.

Os primeiros resultados foram divulgados após seis meses de execução do projeto. As fichas foram apresentadas na forma de mesa de debate e de minicurso, com a participação de discentes universitários e de professores da educação básica. $\mathrm{O}$ objetivo era expor didaticamente o material para que os professores pudessem aplicar nas suas turmas, conforme a disponibilidade e a realidade local. Essa primeira versão das fichas foi disponibilizada para todos os participantes, feita a ressalva de se tratar de material ainda em fase de elaboração. Após os eventos, percebemos que a aproximação dos discente com essas leituras não só amplia sua reflexão, já que ele entra em contato com uma documentação diferente da habitual, mas também constitui um exercício que irá auxiliálo no desenvolvimento e na condução de propostas interdisciplinares próprias. Quanto aos professores atuantes na educação básica, o projeto pretende ampliar as oficinas e incluir alunos do ensino médio no público das apresentações, visando sempre o aprimoramento comunicativo do material.

Num balanço geral, os primeiros resultados foram satisfatórios, atendendo às expectativas dos membros do projeto e, principalmente, tendo êxito no objetivo de estudar as fontes textuais, trabalhar os 
problemas lexicais e encaminhar as exposições teóricas. Os discentes envolvidos no projeto elaboraram 32 fichas de análise que, devidamente revisadas, serão divulgadas nas escolas e publicadas em meio eletrônico, com o intuito de que a produção científica possa transcender os muros da academia e tornar-se acessível a todos os cidadãos.

Assim, nos inserimos em duas frentes de atuação: (1) o fortalecimento dos cursos de História Antiga nas licenciaturas de História, demonstrando para o discente maneiras frutíferas de colocar em diálogo a Antiguidade e a contemporaneidade; (2) o estímulo aos discentes para a reflexão sobre as práticas de ensino de História Antiga para os níveis fundamental e médio. Tais frentes estão em plena atividade, como mostra a recente ampliação de especialistas atuando nas universidades e os diversos projetos preocupados com o ensino da Antiguidade, como o nosso. ${ }^{7}$

\section{Referências}

ADRADOS, F. R. La democracia ateniense. Madrid: Alianza Editorial, 1975.

ARISTÓTELES. Constituição dos atenienses. Tradução de Delfim Ferreira Leão. 3. ed. Lisboa: Fundação Calouste Gulbenkian, 2011.

ARISTÓTELES. Política. Tradução de Danusia Oliveira Ferreira. [2017]. Não publicado.

ARISTÓTELES. Politica. Tradução de António Campelo Amaral e Carlos Gomes. Lisboa: Vega, 1998.

ARNASON, J. P.; RAAFLAUB, K. A.; WAGNER, P. (Eds). The Greek Polis and the Invention of Democracy: A Political-Cultural Transformation and Its Interpretation. Oxford: Wiley-Blackweel, 2013. DOI: https://doi.org/10.1002/9781118561768

BAILLY, A. Le grand Bailly: dictionnaire de grec-français. Paris: Hachette, 2000.

\footnotetext{
${ }^{7}$ Entre esses projetos, destacam-se a coleção didática a respeito de Pompeia, realizada pelo PET/História da UFPR (https://pethistoriaufpr.wordpress.com/), e o projeto "Aprendendo com Clio - Educação Patrimonial e Cultural Material da Antiguidade”, realizado no âmbito do LHIA/Instituto de História da UFRJ (http://aprendendocomclio.wix.com/lhia).
} 
BENVENISTE, É. O vocabulário das instituições indo-européias. Tradução de Denise Bottmann e Eleonora Bottmann. Campinas: Unicamp,1995. v. 2.

BRANDÃO, J. L.; OLIVEIRA, F. de. História de Roma. Das origens à morte de Cesar. Coimbra: Imprensa da Universidade de Coimbra, 2015.

CHANTRAINE, P. Dictionnaire étymologique de la langue grecque. Histoire des mots. Paris: Éditions Klincksieck, 1968.

CHEVITARESE, A. L.; CORNELLI, G.; SILVA, M. A. de O. (Orgs.). A tradição clássica e o Brasil. Brasília: Archai-UNB/Fortium, 2008.

DABDAB TRABULSI, J. A. Participation directe et démocratie grecque: une histoire exemplaire? Besançon: Presses universitares de FrancheComté, 2006.

FINLEY, M. I. Democracia: antiga e moderna. Tradução de Waldéa Barcellos e Sandra Bedran. Rio de Janeiro: Graal, 1988.

GERNET, L. Anthropologie de la Grèce Antique. Paris: Champs Flammarion, 1982a.

GERNET, L. Droit et institutions en Grèce Antique. Paris: Champs Flammarion, 1982b.

GERNET, L. Recherches sur le développement de la pensée juridique et morale en Gréce: Étude sémantique. Paris: Albin Michel, 2002.

GUARINELLO, N. L. História Antiga. São Paulo: Contexto, 2013.

HERÓDOTO. História. Introdução e tradução de Mário da Gama Cury. 2. ed. Brasília: Universidade de Brasília, 1988.

MITCHELL, T. Democracy's Beginning: the Athenian Story. New Haven: Yale University Press, 2015.

OBER, J. The Rise and Fall of Classical Greece. New Jersey: Princeton University Press, 2015. DOI: https://doi.org/10.1515/9781400865550

POLÍBIO. História. Tradução de Mário da Gama Cury. 2. ed. Brasília: Universidade de Brasília, 1996.

POLÍBIO. História. Tradução de Bruno Ramalho de Figueirêdo. [2017]. Não publicado. 
PSEUDO-XENOFONTE. A constituição dos atenienses. Tradução do grego, introdução, notas e índices de Pedro Ribeiro Martins. Coimbra: IUC, 2012.

SILVA, L. L. T. da; GONÇALVES, J. W. O ensino de História Antiga: algumas reflexões. In: SIMPÓSIO NACIONAL DE HISTÓRIA, 28., 2015, Florianópolis. Anais eletrônicos... Disponível em: $<\mathrm{http}: / / \mathrm{www}$. snh2015.anpuh.org/resources/anais/39/1434418680_ARQUIVO OENSINODEHISTORIAANTIGA.anpuh.doc,p.pdf $>$. Acesso em: $\overline{5}$ maio 2017. DOI: https://doi.org/10.5433/2238-3018.2015v21n1p135

SILVA, S. C. Aspectos do ensino de História Antiga no Brasil: algumas reflexões. Alétheia: revista de estudos sobre Antiguidade e Medievo, Jaguarão, v. 1, p. 145-155, jan.-jul. 2010.

VEYNE, P. Acreditavam os gregos nos seus mitos? Ensaios sobre a imaginação constituinte. Tradução de Horácio Gonzalez e Milton Meira Nascimento. São Paulo: Brasiliense, 1984. 


\section{Anexo}

\begin{tabular}{|c|c|}
\hline 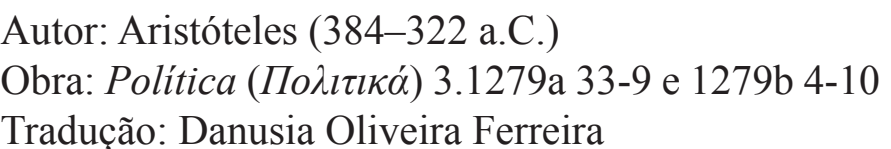 & \\
\hline
\end{tabular}

Dentre as monarquias, costumamos chamar de realeza aquela que visa o benefício coletivo. Quando o governo é de poucos, porém mais do que um, costumamos chamar de aristocracia (ou porque os melhores governam, ou porque visa o melhor para a cidade e para os que participam de sua coletividade). Já quando o conjunto dos cidadãos participa da política visando o benefício coletivo, é chamada pelo nome comum a todos os regimes: politeia. [...] São transgressões dos anteriores: a tirania, da realeza; a oligarquia, da aristocracia; e a democracia, da politeia. Porque a tirania é a monarquia voltada ao benefício do monarca, a oligarquia é o regime voltado ao benefício dos ricos, e a democracia é o regime voltado ao benefício dos pobres: nenhum deles, portanto, se volta para o que é vantajoso para o coletivo.

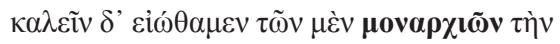

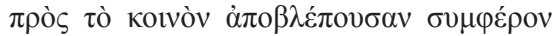

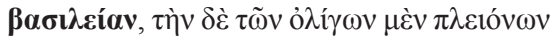

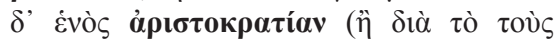

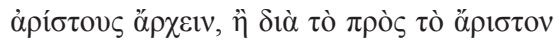

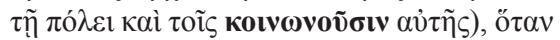

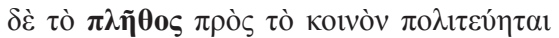

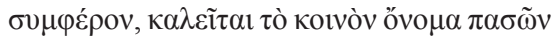

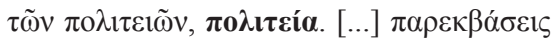

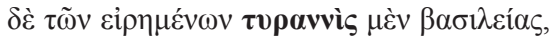

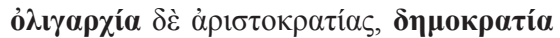

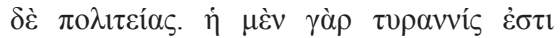

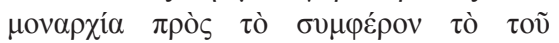

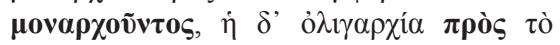

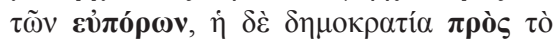

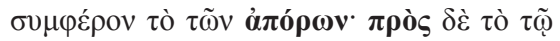

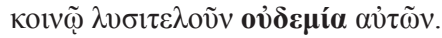




\section{Léxico}

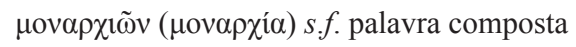
pelos termos $\mu$ óvos ("só", "único"), e ’ $\rho \chi o ́ \varsigma$ ("aquele que conduz", "o guia", "o mais poderoso"); daí o sentido de "comando de um só", e, por conseguinte, "poder monárquico". O termo na sua acepção etimológica ("poder exercido por um só") adquire a designação específica de "realeza" ou "tirania", consoante se trate respectivamente de um poder unipessoal reto ou desviado.

$\beta \alpha \sigma i \lambda \varepsilon i ́ \alpha v(\beta \alpha \sigma i ́ \lambda \varepsilon 1 \alpha)$ s.f. "realeza", "reino"; derivado de $\beta \alpha \sigma \imath \lambda \varepsilon v ́ \varsigma$ ("comandante", "rei", "soberano") palavra que define a realeza homérica; o basiléus de Homero não é um monarca absoluto, mas o primeiro dentre seus iguais, como que "o rei dos reis".

$\delta \eta \mu о к \rho \alpha i ́ \alpha$ s.f. palavra composta pelos

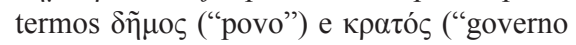
com base no poder popular").

$\pi \lambda \tilde{\eta} \theta$ o s.m. com ideia de número: "grande quantidade"; "muitos". Com sentido de pessoas: "multidão"; "massa numerosa".

$\mu о v \alpha \rho \chi 0 \tilde{v} \tau \sigma \varsigma(\mu о v \alpha \rho \chi \varepsilon \dot{\varepsilon} \omega)$ v. "reinar com soberania". O particípio expressa o sentido do poder tirânico de comandar sozinho, visando sempre o interesse individual.

$\pi \rho \grave{\varsigma}$ prep. valor semântico que aponta a proveniência de cada regime conforme seu interesse particular (p. ex. "a democracia provém do interesse dos pobres", " $\pi \rho$ ò $\varsigma$ ì

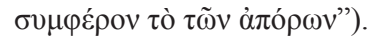

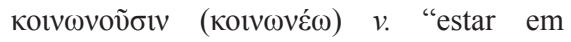
comunidade com"; "fazer parte"; "associarse", "aliar-se"; (deriva de кovvós, "comum”).

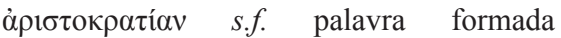
pela composição dos termos ö $\rho \leftarrow \sigma \tau \varsigma$ ("excelente", "o melhor", "o mais nobre")

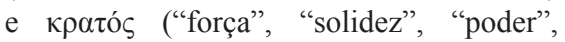
“domínio"). Daí depreende-se os sentidos: "governo dos mais poderosos"; "governo ideal dos melhores".

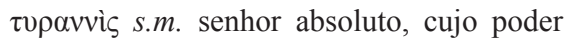
não está limitado pelas leis; aquele que usurpa o poder absoluto em um estado livre.

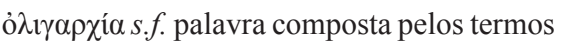
ỏ $\lambda$ íros ("pouco", se tratando de número

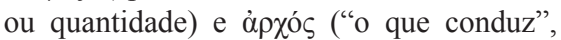
"guia", "o mais poderoso"), resultando em "pequeno número de homens que detém o poder".

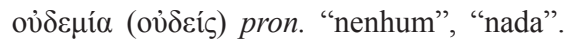
Para Aristóteles, nenhum dos regimes provém do interesse comum ou da comunidade.

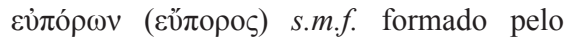
prefixo \&ű ("bom") significa, literariamente, "fácil passagem", "acesso". Entende-se seu sentido no texto, em referência aos ricos, como aqueles cidadãos que dispõem de fáceis recursos ou abundantes.

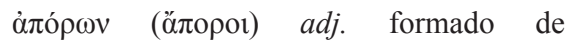

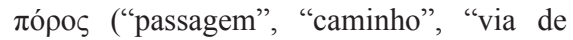
comunicação") com o prefixo de negação o̊: "sem passagem”, “impossível”, "impraticável", "difícil”; por conseguinte, "vida humilde", "pobre". 


\section{Comentário}

Neste trecho notamos a classificação conceitual dos regimes, passo importante para o tratado aristotélico da Política. Se inicialmente o autor apresenta um vetor quantitativo de tipos de regime em função do número de governantes, aqui traça uma classificação qualitativa com critérios que permitem discernir os regimes retos dos seus respectivos desvios.

O termo $\pi 0 \lambda \imath \tau \varepsilon i ́ \alpha$ neste trecho adquire o sentido de "regime constitucional", isto é, o regime reto exercido por muitos cidadãos em vista do bem comum. O regime não tem nome específico, como os demais. Designado pela palavra $\pi$ o $\lambda \imath \tau \varepsilon i ́ \alpha$, ele se torna comum a todos os regimes, como se adquirisse a essência de todo regime verdadeiramente político. Para Aristóteles, o regime constitucional se faz presente em uma comunidade de iguais em que todos os cidadãos governam, isto é, que sejam alternadamente governante e governados, sempre com vistas ao interesse comum.

A aristocracia, para o filósofo, é um regime estabelecido pelos melhores cidadãos de acordo com a virtude, em termos absolutos, e não por indivíduos honestos sob um determinado aspecto. Apenas na aristocracia

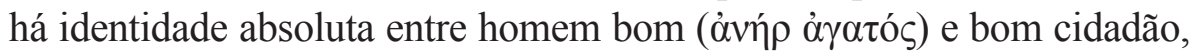

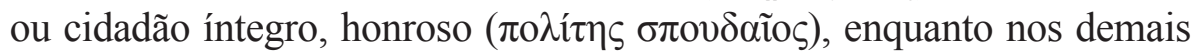
regimes os bons cidadãos só são bons em relação ao seu próprio regime. Para Aristóteles, como a comunidade é o regime político, a virtude do cidadão deve necessariamente ser relativa ao regime, pois, se há diferentes modalidades de regime, não pode existir uma única virtude perfeita do bom cidadão. Mas o homem bom é chamado "bom" devido a uma virtude única, a virtude perfeita. A escolha dos magistrados é realizada não só de acordo com a riqueza dos cidadãos, mas também de acordo com a virtude. Em Aristóteles, a aristocracia atende à riqueza e à virtude.

A realeza, para Aristóteles, revela uma índole aristocrática (posto que o poder real se funda no primado da excelência, do mérito e da virtude). Na realeza, o rei é escolhido dentre as facções que se notabilizam, quer pela superioridade da sua virtude, quer pelos feitos que advêm dessa conduta virtuosa, acrescidos da capacidade do governante. Já a tirania apresenta-se como um composto de oligarquia e democracia nas suas formas extremas. Por esse motivo, é o tipo de regime mais nefasto, segundo o filósofo, para os que são governados, uma vez que, 
combinando o que há de mau nos dois regimes, acumula os desvios e os defeitos em que ambos incorrem. Para Aristóteles, quase todos os tiranos surgem das fileiras demagógicas (Pisístrato, em Atenas, é um exemplo citado por Aristóteles) e conquistam a confiança popular através da difamação dos notáveis. Porém, outras tiranias anteriores surgiram de realezas em que os reis desprezaram a raiz hereditária da sua dignidade e aspiraram a um poder despótico; outras, enfim, nasceram dos oligarcas que elegiam um dentre eles para as magistraturas mais importantes.

\section{Tópicos para discussão}

- Discutir a classificação dos regimes políticos na Antiguidade Clássica grega.

- Debater sobre as diferenças entre os regimes retos e os desviados.

- Trabalhar com a formação das palavras monarquia, oligarquia, aristocracia e democracia.

Quadro comparativo

\begin{tabular}{|c|c|c|c|}
\hline & 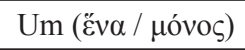 & Poucos (ỏhíyol) & Muitos ( $\left(\pi \lambda_{\lambda o \imath}\right)$ \\
\hline \multicolumn{4}{|c|}{ Regimes retos: interesse comum (formas positivas) } \\
\hline Tipo de Regime & Realeza & Aristocracia & Constitucional ( $\pi 0 \lambda \iota \tau \varepsilon i ́ \alpha)$ \\
\hline Critério & 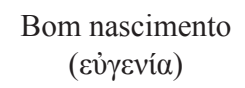 & 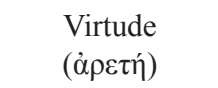 & 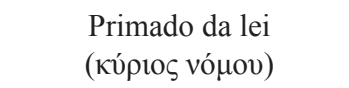 \\
\hline Meio & 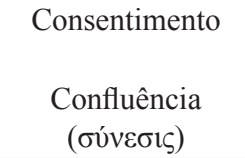 & $\begin{array}{l}\text { Mérito } \\
(\dot{\alpha} \xi i ́ \alpha)\end{array}$ & $\begin{array}{l}\text { Meio-termo } \\
(\mu \varepsilon ́ \sigma o \varsigma)\end{array}$ \\
\hline Finalidade & $\begin{array}{l}\text { Ordenança } \\
\quad(\tau \alpha \dot{\xi} \xi \varsigma)\end{array}$ & 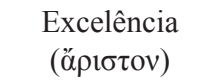 & $\begin{array}{l}\text { Estabilidade } \\
(\dot{\alpha} \sigma \varphi \alpha ́ \lambda \varepsilon 1 \alpha)\end{array}$ \\
\hline \multicolumn{4}{|c|}{ Regimes desviados: interesse particular (formas negativas) } \\
\hline Tipo de Regime & Tirania & Oligarquia & Democracia/Demagogia \\
\hline Critério & $\begin{array}{l}\text { Arbítrio } \\
(\tau \varepsilon ́ \lambda \varepsilon \sigma 1 \zeta)\end{array}$ & 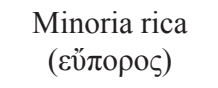 & $\begin{array}{l}\text { Maioria pobre } \\
\quad(\alpha \alpha \pi \circ \rho \circ \varsigma)\end{array}$ \\
\hline Meio & 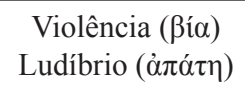 & 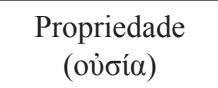 & $\begin{array}{c}\text { Liberdade } \\
(\dot{\varepsilon} \lambda \varepsilon v \theta \varepsilon \rho i ́ \alpha)\end{array}$ \\
\hline Finalidade & $\begin{array}{l}\text { Medo } \\
(\varphi o ́ \beta o \varsigma)\end{array}$ & 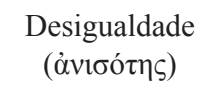 & 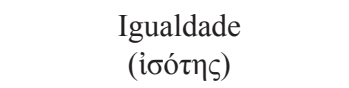 \\
\hline
\end{tabular}




\section{Referências}

ARISTÓTELES. Política. Tradução de António Campelo Amaral e Carlos Gomes. Lisboa: Vega, 1998.

ARISTOTLE. Politics. Ed. W. D. Ross. Oxford: Clarendon Press, 1957. Disponível em: $<$ http://www.perseus.tufts.edu/hopper/text?doc=Perseus: text:1999.01.0057>. Acesso em: 5 maio 2017.

BAILLY, A. Dictionnaire grec-français. Paris: Hachette, 2000.

CHANTRAINE, P. Dictionnaire étymologique de la langue grecque. Histoire des mots. Paris: Éditions Klincksieck, 1968. 